\title{
ARTRITE REACTIVA (SYN: SÍNDROME DE REITER)
}

Joana Antunes, João Borges da Costa, Manuel Sacramento Marques

Clínica Dermatológica Universitária, Hospital de Santa Maria, Centro Hospitalar Lisboa Norte, EPE, Lisboa

RESUMO - Artrite reactiva, anteriormente conhecida como Síndrome de Reiter, refere-se à tríade clássica de artrite, uretrite e conjuntivite, que ocorre após episódio de infecção génito-urinária ou gastrointestinal. Nos adultos, a causa mais frequente é a infecção por Chlamydia trachomatis. Pode também apresentar-se sem todos os elementos da tríade, ou acompanhar-se de manifestações cutâneas ou viscerais. Enquadra-se no grupo das espondiloartropatias seronegativas, e existe uma forte associação com o gene HLA-B27. A doença pode ocorrer de forma aguda ou evoluir para a cronicidade. $O$ tratamento vai depender da infecção desencadeante.

PALAVRAS-CHAVE - Artrite reactiva; Síndrome de Reiter; Espondiloartropatia; Queratoderma blenorrágico; Balanite circinada.

\section{REACTIVE ARTHRITIS (SYN: REITER'S SYNDROME)}

ABSTRACT - Reactive arthritis, previously known as Reiter's Syndrome, is the classic triad of arthritis, urethritis and conjunctivitis, which occurs after an acute episode of genito-urinary or gastrointestinal infection. In adults, the most frequent cause is infection by Chlamydia trahomatis. It may also present as an incomplete triad or be associated with dermatological or visceral symptoms. It is classified as a seronegative spondyloarthropathy, and is strongly associated with HLA-B27. Reactive arthritis may occur as an acute disease or progress to a chronic form, and treatment depends on the eliciting infection.

KEY-WORDS - Reactive arthritis; Reiter's syndrome; Spondyloarthropathy; Keratoderma blennorrhagicum; Circinate balanitis.

Dr.. Joana Antunes

Clínica Dermatológica Universitária, Hospital de Santa Maria

Av. Prof. Egas Moniz

1649-035 Lisboa

Tel.: 931198848

E-mail: joana_antunes@yahoo.com 


\section{INTRODUÇÃO}

Aproximadamente em 460 a.C., Hipócrates terá feito a primeira descrição deste síndrome, ao referir que "os adultos jovens do sexo masculino apenas sofriam de gota após o início da actividade sexual" (à época, gota era sinónimo de artrite aguda) ${ }^{1}$. Em 1916, em plena I Guerra Mundial, durante a Batalha de Somme, dois médicos franceses, Fiessinger e Leroy, descreveram a clássica tríade de artrite, uretrite e conjuntivite, após um caso de infecção por Shigella ${ }^{2}$. No mesmo ano, Hans Reiter reportou um caso de artrite, uretrite não-gonocócica e conjuntivite num soldado alemão, igualmente após um episódio de desinteria ${ }^{3}$. Em 1942, Baver e Engelman, ao reconhecerem o mesmo síndrome e, apercebendo-se que este havia já sido descrito por Reiter, optaram por denominá-lo de Síndrome de Reiter ${ }^{4}$. No entanto, após o reconhecimento de que Hans Reiter terá sido um colaborador activo do regime Nazi, foi proposta a substituição do epónimo Síndrome de Reiter pela denominação Artrite Reactiva (AR)5, e esta sugestão foi aceite pela comunidade médica internacional. Numa tentativa de padronizar os critérios diagnósticos da AR, no $4^{\text {th }}$ International Workshop on Reactive Arthritis, concordou-se que este termo deveria apenas aplicar-se a doentes com artrite pós-infecciosa que preenchessem os critérios de espondiloartropatia seronegativa (doentes com doseamento de Factor Reumatóide negativo) ${ }^{6}$. Esta classificação permitiu excluir outras artrites pós-infecciosas, como é o caso da Febre Reumática ou Doença de Lyme?.

\section{EPIDEMIOLOGIA}

A falta de uniformização nos critérios de diagnóstico, bem como a dificuldade na definição da própria doença, vem dificultar os registos epidemiológicos. Habitualmente, consideram-se 2 tipos diferentes de AR: epidémica ou pós-desintérica e endémica ou adquirida por via sexual (SARA) ${ }^{2}$. Nos Estados Unidos da América (EUA) e Grã-Bretanha, a forma endémica é a mais frequentemente observada. No restante continente Europeu e em África, a forma pós-desintérica é a mais comum ${ }^{7}$.

Os dados de incidência a nível mundial são extremamente variáveis, oscilando entre 30 a 200 casos por 100.000 pessoas $^{1}$. Esta disparidade pode ser, em parte, explicada por diferentes substratos genéticos entre as populações estudadas, nomeadamente diferenças na prevalência do gene HLA-B2 $7^{4}$.
Relativamente à idade, o pico de incidência da $A R$ localiza-se na terceira década de vida. No entanto, também pode ocorrer em crianças, nomeadamente AR pós-desintérica, ou em doentes idosos.

Enquanto que a AR que surge após episódio de infecção entérica ocorre com frequência semelhante em indivíduos do sexo masculino e feminino, os casos desencadeados por infecção venérea, são cerca de 20 vezes mais comuns em homens. Bas e cols. ${ }^{8}$ postularam que, nos casos de SARA causada por Chlamydia trachomatis, este fenómeno se poderia dever a defeitos inatos na imunidade humoral, nos indivíduos do sexo masculino. Na realidade, verificaram que, homens incapazes de produzir anticorpos em quantidade suficiente, permitiam uma maior disseminação das bactérias pelo organismo. Observaram ainda que os efeitos das hormonas sexuais ao nível das respostas imunes locais, durante as fases iniciais da infecção, também seriam factores determinantes.

Chlamydia, Salmonella, Shigella, Campylobacter e Yersinia são as bactérias frequentemente associadas ao desenvolvimento de AR (Quadro I). A frequência de indivíduos infectados com bactérias artritogénicas que vêm, na realidade, a desenvolver AR é cerca de 1 a $4 \%$ $(4,1 \%$ no caso de doentes que sofreram infecção aguda a C. trachomatis) ${ }^{9}$. Todavia, sabe-se que este risco sobe para $20 \%$, nos indivíduos positivos para HLA-B2710. Por outro lado, 70 a $90 \%$ dos doentes com AR são positivos para este gene, cuja prevalência na população em geral ronda os $10 \%$. Todavia, não parece existir qualquer vantagem na determinação rotineira do status HLA-B27.

\section{FISIOPATOLOGIA}

Apesar de as manifestações clínicas de AR endémica e epidémica serem semelhantes, parece haver algumas diferenças na fisiopatologia destas duas entidades. A ocorrência de AR depende de diversos factores, nomeadamente da interacção entre elementos infecciosos e imunológicos. Pensa-se que a presença de bactérias e dos seus produtos a nível das articulações, e a resposta imunológica local por estes desencadeada, seja uma etapa fundamental na patogénese da AR. Esta hipótese é sustentada por vários estudos, em que o ADN de agentes desencadeadores de AR foi isolado dos tecidos sinoviais de doentes com $A R^{11,12}$. Além disso, em casos de AR pós-infecção por Chlamydia, foi possível isolar do tecido sinovial as próprias bactérias $^{13}$. 


\section{Quadro I}

\begin{tabular}{|c|c|c|}
\hline Tracto Génito-Urinário & Tracto Gastrointestinal & Tracto Respiratório \\
\hline $\begin{array}{l}\text { - Chlamydia trachomatis } \\
\text { - Neisseria gonorrhaeae } \\
\text { - Mycoplasma fermentans } \\
\text { - Mycoplasma genitalium } \\
\text { - Ureaplasma urealyticum }\end{array}$ & $\begin{array}{l}\text { - Shigella flexneri } \\
\text { - Salmonella enteritidis } \\
\text { - Salmonella typhimurum } \\
\text { - Yersinia enterocolitica } \\
\text { - Campylobacter jejuni } \\
\text { - Escherichia coli } \\
\text { - Cryptosporidium } \\
\text { - Entamoeba histolytica } \\
\text { - Giardia lamblia } \\
\text { - Brucella abortus } \\
\text { - Clostridium difficile }\end{array}$ & $\begin{array}{l}\text { - Streptococcus pyogenes } \\
\text { - Chlamydia pneumoniae } \\
\text { - Chlamydia psitacci }\end{array}$ \\
\hline
\end{tabular}

Dada a associação da AR com o gene HLA-B27, foi postulado que poderia existir reactividade cruzada entre os anticorpos desenvolvidos contra a infecção original e o HLA-B27 14 . No entanto, outro estudo mostrou que este mimetismo molecular não é exclusivo das bactérias passíveis de originar $A R^{15}$, pelo que o papel da reactividade cruzada não será tão importante como inicialmente pensado.

Outros estudos sugerem que o desequilíbrio entre várias citocinas, nomeadamente factor de necrose tumoral- $\alpha$, interleucina (IL)-2, IL-10, interferão- $\gamma$, se pode relacionar com o desenvolvimento da doença' ${ }^{1}$.

A AR tem sido reportada em até $11 \%$ dos doentes seropositivos para $\circ \mathrm{VIH}^{15}$, o que sugere que as células $T$ helper não deverão ter um papel fundamental na sua patogénese. Por outro lado, o próprio $\mathrm{VIH}$ pode ser causador de artrite ou aumentar a susceptibilidade para infecção por bactérias artritogénicas.

\section{MANIFESTAÇÕES CLÍNICAS}

O espectro de manifestações associado à $A R$ é amplo, com gravidade e duração de doença variáveis. Os sintomas predominantes no quadro clínico podem ainda ser diferentes de doente, para doente. Esta variabilidade de apresentações da doença, é um dos responsáveis pela dificuldade de diagnóstico, inclusive na própria elaboração dos critérios diagnósticos.

Os sintomas surgem, em média, 4 semanas após o episódio infeccioso. Apesar do reconhecimento do evento infeccioso ser fundamental para o diagnóstico, este pode ocasionalmente não ser valorizado pelo próprio doente, como é o caso de episódios transitórios de diarreia ou, muitas vezes, das infecções a Chlamydia.
Por vezes, o quadro de $A R$ pode surgir vários meses após a infecção causal ${ }^{16}$. No entanto, alguns doentes não apresentam os vários sintomas simultaneamente, podendo mesmo estes manifestarem-se com anos de intervalo ${ }^{17}$.

A sintomatologia associada a AR é variada, e vai muito para além da clássica tríade de artrite, uretrite e conjuntivite (Quadro II). Os sintomas agudos e crónicos incluem manifestações articulares e tendinosas, mucoutâneas, oculares e, ocasionalmente, viscerais. Podem ainda ocorrer sinais de doença sistémica, tais como febre, mal-estar geral e perda ponderal ${ }^{15}$, sobretudo na fase aguda da doença.

\section{Quadro II}

\begin{tabular}{l|l}
\multicolumn{2}{c}{ MANIFESTAÇÕES CLÍNICAS } \\
ASSOCIADAS A ARTRITE REACTIVA \\
\hline Reumatológicas & Artrite, entesite \\
\hline Cutâneas & $\begin{array}{l}\text { Queratoderma blenorrágico, balanite/vulvite } \\
\text { circinada, onicodistrofia }\end{array}$ \\
\hline Mucosas & Máculas eritematosas, pápulas, placas, erosões \\
\hline Urogenitais & Uretrite, cervicite, prostatite \\
\hline Oftalmológicas & Conjuntivite, uveíte, queratite \\
\hline Viscerais & $\begin{array}{l}\text { Alterações cardíacas, renais, gastrointestinais, } \\
\text { neurológicas }\end{array}$ \\
\hline
\end{tabular}

Estima-se que aproximadamente 30 a $50 \%$ dos doentes com AR evolvem para cronicidade ${ }^{4}$. Essa tendência é maior nos doentes HLA-B27 positivos, que também parecem ter doença mais grave, com maior frequência de uveíte e sacroileíte ${ }^{18}$. 


\section{Sistema músculo-esquelético}

A principal manifestação da AR é a artrite, que ocorre em cerca de $95 \%$ dos $\operatorname{casos}^{19}$, muitas vezes como primeira queixa ${ }^{20}$. Tipicamente, trata-se de uma oligoartrite aguda, assimétrica, afectando sobretudo os joeIhos, articulações tibio-társicas e metatarso-falângicas. Os sintomas clássicos incluem dor, rigidez após repouso prolongado, e alívio com o exercício. Lombalgia e dactilite com "dedo em salsicha" ${ }^{20}$ (Fig. 1), também são características da apresentação inicial. A entesite é a lesão elementar das espondilartropatias e corresponde à inflamação dos ligamentos ou tendões no seu ponto de inserção no osso, manifestando-se como dor localizada e edema. No caso da $A R$, entesite do ponto de inserção do tendão de Aquiles no calcâneo é responsável pelo clássico talon douloureux (calcanhar doloroso), descrito por Fournier em 18683. Aproximadamente 25\% dos doentes com AR crónica desenvolvem sacroileíte ou espondilite anquilosante ${ }^{21}$.

\section{Envolvimento mucocutâneo (Quadro III)}

A manifestação cutânea mais característica da AR é o queratoderma blenorrágico, embora estas lesões apenas surjam em 5 a $10 \%$ dos doentes ${ }^{19}$. Tratam-se de máculas eritematosas, que atingem preferencialmente as palmas e plantas, mas que também podem surgir nas superfícies extensoras dos membros inferiores, pés, mãos, dedos e couro cabeludo (Figs. 2 e 3). Rapidamente se transformam em pápulas e pseudo-

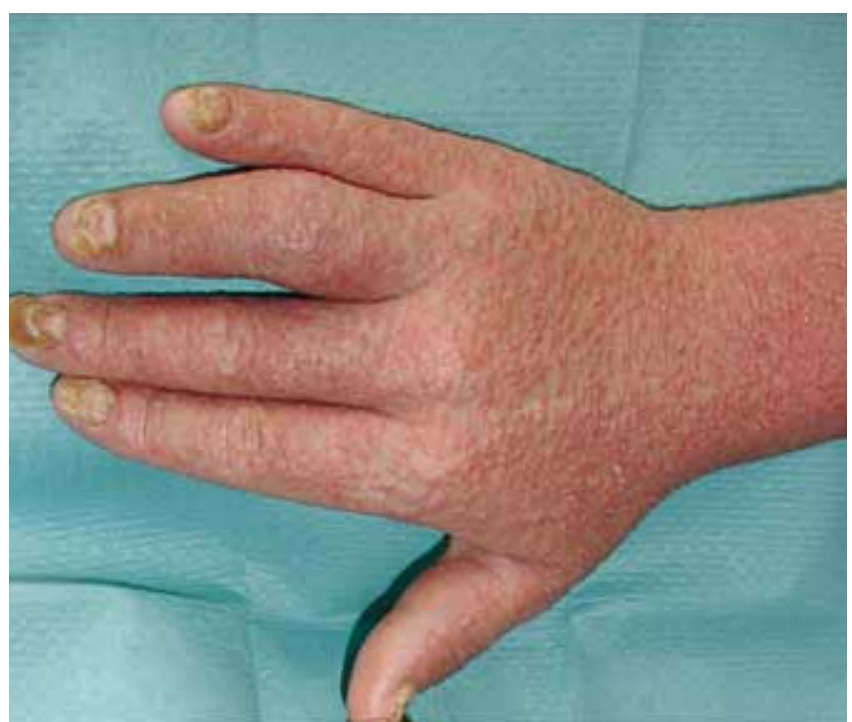

Fig. 1 - Dactilite do $4^{\circ}$ dedo da mão direita em doente com Artrite Reactiva. Note as pápulas eritematosas psoriasiformes correspondentes ao queratoderma blenorrágico e as alterações ungueais.

vesículas, adoptando uma coloração alaranjada à medida que a sua superfície se torna hiperqueratósica, podendo mesmo formar placas. Clínica e histologicamente, podem ser indistinguíveis de psoríase pustulosa, e ainda acompanhar-se de onicodistrofia semelhante à observada na psoríase ungueal. Habitualmente, estas

\section{Quadro III}

\section{MANIFESTAÇÕES DERMATOLÓGICAS ASSOCIADAS A ARTRITE REACTIVA}

\begin{tabular}{|c|c|c|}
\hline & $\%$ Doentes & Apresentação \\
\hline $\begin{array}{l}\text { Queratoderma } \\
\text { blenorrágico }\end{array}$ & $\cong 10 \%$ & $\begin{array}{l}\text { Inicialmente, máculas e vesículas eritematosas nas palmas e plantas, que progridem para pápulas, } \\
\text { pústulas e placas hiperqueratósicas. } \\
\text { Também podem surgir no tronco, couro cabeludo, superfície extensora dos membros inferiores e dorso } \\
\text { dos dedos. Semelhante a psoríase pustulosa. }\end{array}$ \\
\hline $\begin{array}{l}\text { Balanite } \\
\text { circinada }\end{array}$ & Até $50 \%$ & $\begin{array}{l}\text { Homens circuncisados: placas hiperqueratósicas na glande. } \\
\text { Homens não-circuncisados: pequenas vesículas/pústulas que rompem originando erosões superficiais } \\
\text { indolores, e coalescem formando um padrão serpinginoso bem demarcado. }\end{array}$ \\
\hline $\begin{array}{l}\text { Vulvite } \\
\text { ulcerada }\end{array}$ & $\begin{array}{l}\text { Menos comum } \\
\text { que balanite }\end{array}$ & $\begin{array}{l}\text { Semelhante à balanite circinada. } \\
\text { Placas avermelhadas, com crosta, na vulva e períneo. } \\
\text { Pápulas nas áreas pilosas da vulva, pequenos lábios e vestíbulo vulvar. } \\
\text { Erosões superficiais bem delimitadas, disseminadas sobre toda a região genital. } \\
\text { Ocasionalmente, corrimento vaginal. }\end{array}$ \\
\hline $\begin{array}{l}\text { Alterações } \\
\text { ungueais }\end{array}$ & $20-30 \%$ & $\begin{array}{l}\text { Semelhante a psoríase ungueal; onicólise, hiperqueratose subungueal, pústulas periungueais. } \\
\text { Ocasionalmente, picotado ungueal secundário a inflamação da prega ungueal proximal. }\end{array}$ \\
\hline Lesões orais & $9-40 \%$ & $\begin{array}{l}\text { Indolores, podem ser negligenciadas pelo doente. } \\
\text { Incluem erosões no palato e mucosa oral, glossite e língua geográfica. }\end{array}$ \\
\hline
\end{tabular}

Adaptado de Wu IB, Schwartz RA: Reiter's syndrome: The classic triad and more. J Am Acad Dermatol 59:1 13-21 (2008) 


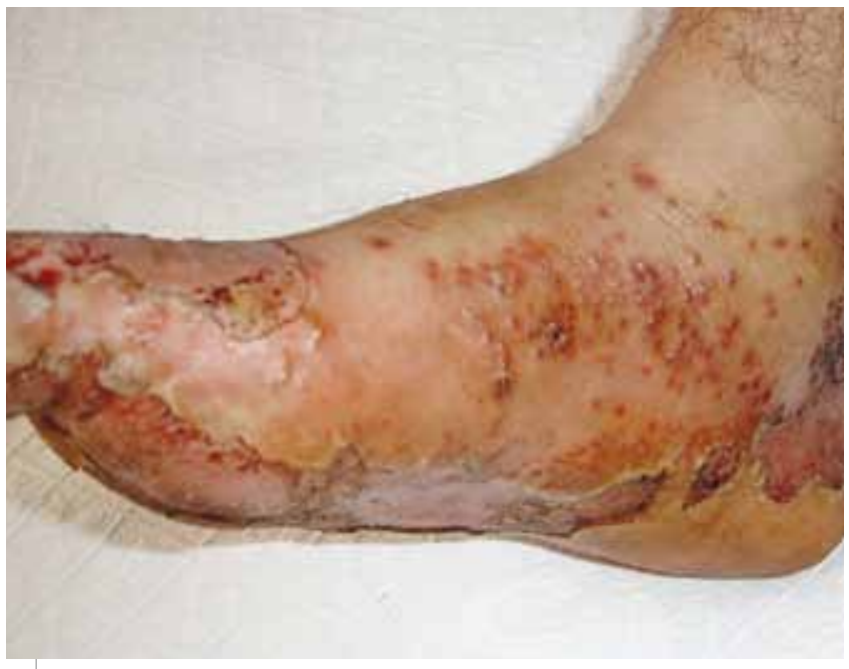

Fig. 2 - Queratoderma blenorrágico com atingimento da planta.

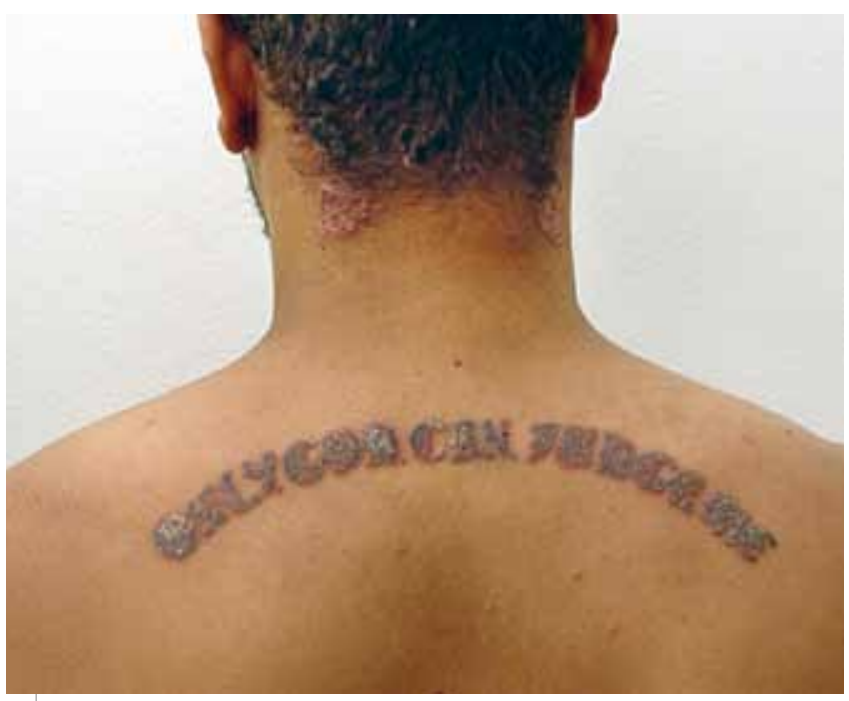

Fig. 3 - As lesões de queratoderma blenorrágico podem ser clinicamente indistinguíveis de psoríase. Note neste caso fenómeno de Koebner sobre tatuagem.

lesões surgem 1 a 2 meses após o aparecimento da artrite, mas também podem surgir concomitantemente ou, mais raramente, antecedê-la ${ }^{22}$. Ocasionalmente, podem evoluir para eritrodermia, sobretudo em doentes seropositivos para o $\mathrm{VIH}$.

A balanite circinada é talvez a manifestação cutânea mais frequentemente associada a $A R^{2}$. Caracteriza-se por lesões psoriasiformes, superficiais, indolores, que surgem principalmente sobre a glande mas que também podem atingir o corpo do pénis e escroto. Ao coalescerem, as lesões adquirem o típico aspecto circinado. Nos homens circuncisados, as lesões são mais secas e consistem em placas hiperqueratósicas, semeIhantes ao queratoderma.

Nos doentes com $A R$, podem ainda surgir outro tipo de lesões cutâneas, embora com menos frequência. São exemplos: erosões indolores da mucosa oral, palato e língua, língua geográfica e pioderma gangrenoso ${ }^{15}$. $\mathrm{O}$ eritema nodoso, apesar de não ser uma manifestação típica da $A R$, pode ocorrer durante episódios de AR pós-desintérica ${ }^{15}$.

\section{Envolvimento ocular}

A conjuntivite é uma manifestação cardinal da clássica tríade da $A R$, ocorrendo em 30 a $60 \%$ dos doentes $^{19}$. É um sintoma precoce, que pode preceder o aparecimento de artrite. Habitualmente é bilateral, com olho vermelho e escasso exsudado mucopurulento (Fig. 4). A intensidade é variável, podendo passar despercebida pelo doente.

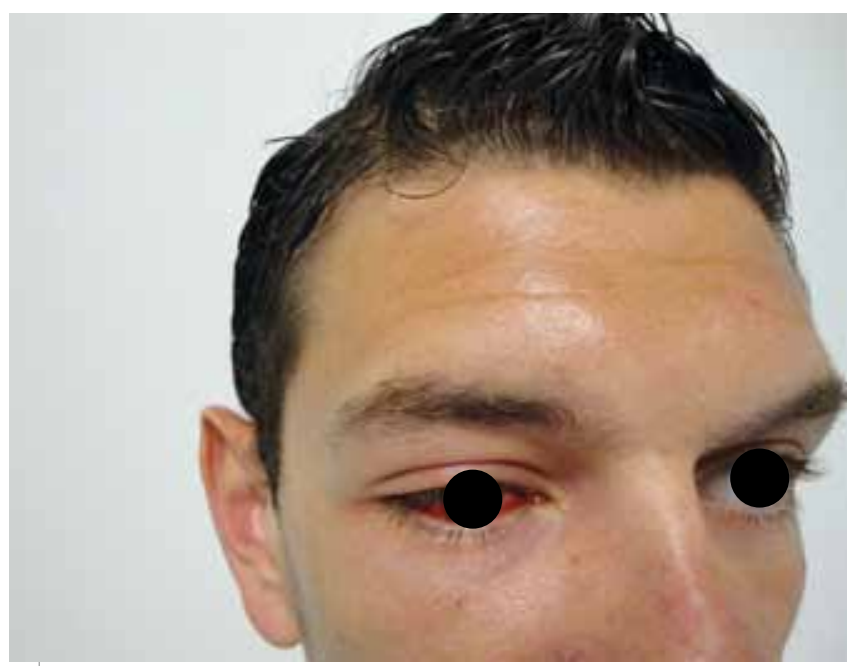

Fig. 4 - Conjuntivite em doente com Artrite Reactiva pós-infecção por C. trachomatis.

A uveíte é menos frequente no período inicial da doença, mas ocorre em $15 \%$ dos doentes com AR recidivante ${ }^{23}$. Tipicamente é unilateral, manifestando-se como olho vermelho, dor ocular, fotofobia e miose. Queratite e episclerite são outras manifestações possíveis nos doentes com $A R$, embora menos comuns. Dado o risco de rápida progressão para cegueira, sobretudo nos doentes com uveíte, é fundamental o acompanhamento oftalmológico nestes doentes ${ }^{15}$. 


\section{Sistema génito-urinário}

A SARA está invariavelmente associada a uretrite ou cervicite, mas estas manifestações também podem ocorrer nos casos de AR pós-desintérica. É frequente preceder $O$ aparecimento de conjuntivite e artrite e manifesta-se como corrimento uretral/vaginal, não purulento e indolor. Alguns doentes referem disúria e hematúria, mas pode ser assintomática. Nos homens, prostatite é uma complicação possível. Glomerulonefrite e nefropatia $\lg A$ são complicações raras ${ }^{24}$.

\section{Envolvimento visceral}

O envolvimento visceral na AR é pouco frequente e, quando ocorre, é equivalente ao encontrado nas restantes espondiloartropatias.

Erosões micro e macroscópicas a nível do intestino delgado e cólon, semelhantes a doença inflamatória intestinal, surgem em vários doentes com $A R$, incluindo aqueles com SARA. Podem ser assintomáticas, agudas ou crónicas. A gravidade dos sintomas gastrointestinais, nomeadamente da diarreia, não se correlaciona necessariamente com a gravidade da artrite.

Podem detectar-se alterações da condução cardíaca no ECG destes doentes, que não costumam ter grande significado clínico. Em fases mais avançadas da doença, alterações valvulares são as complicações cardíacas mais comuns.

\section{DIAGNÓSTICO}

O diagnóstico de AR deve ser feito através da anamnese e do exame objectivo. No entanto, este pode ser dificultado pela multiplicidade de apresentações clínicas possíveis, por casos em que a tríade clássica se encontra incompleta, ou pela disparidade temporal entre o aparecimento dos vários sintomas ${ }^{25}$. Outra dificuldade prende-se com o facto de não existir um exame complementar de diagnóstico específico capaz de diagnosticar com certeza AR.

Os critérios de diagnóstico elaborados pela American Rheumatism Association, em 1981, requerem um episódio de artrite periférica com duração superior a 1 mês, associada a uretrite, cervicite, ou ambas ${ }^{20}$. O mesmo grupo atribui sensibilidade de $84,3 \%$ e especificidade de $98,2 \%$ a esta definição ${ }^{20}$. Atribuem ainda sensibilidade de apenas $50,6 \%$ e especificidade de $98,9 \%$ à tríade de artrite, conjuntivite e uretrite ${ }^{20}$.

A identificação de uma infecção recente é fundamental para o diagnóstico de AR. Dessa forma, uma anamnese detalhada deve procurar queixas gastrointestinais, genito-urinárias ou respiratórias prévias. No caso particular de SARA, deve obter-se uma história sexual completa, sobretudo de novos parceiros sexuais nos 3 meses anteriores.

As análises laboratoriais podem revelar leucocitose, neutrofilia, trombocitose, anemia de doença crónica, velocidade de sedimentação e proteína C-reactiva elevadas (proteína $\mathrm{C}$-reactiva pode normalizar na doença avançada). A pesquisa de Factor Reumatóide e auto-anticorpos é tipicamente negativa.

A coprocultura, urocultura, exame directo e cultura de exsudado uretral, justificam-se dependendo do contexto epidemiológico. Apesar de a infecção por C. trachomatis estar particularmente ligada ao desenvolvimento de SARA, outras infecções sexualmente transmissíveis devem ser igualmente excluídas.

Nas fases iniciais da doença, radiografias das articulações afectadas podem não mostrar alterações, ou revelar apenas sinais inespecíficos de osteopénia ou edema dos tecidos moles. Na doença avançada, podem observar-se os característicos esporões ósseos. O diagnóstico precoce de sacroileíte pode ser feito por ressonância magnética.

\section{DIAGNÓSTICO DIFERENCIAL}

A exclusão de outros diagnósticos possíveis, é uma etapa essencial no processo de diagnóstico da AR (Quadro IV). As restantes espondiloartropatias seronegativas, artrite gotosa, artrite séptica, artrite psoriática e artrite gonocócica, devem fazer parte do diagnóstico diferencial de AR. As manifestações cutâneas podem muitas vezes assemelhar-se a psoríase pustulosa, doença de Behçet, eczema atópico ou sífilis secundária.

\section{Quadro IV}

\begin{tabular}{l|l}
\multicolumn{2}{c}{\begin{tabular}{c}
\multicolumn{1}{c}{ DIAGNÓSTICO DIFERENCIAL } \\
DE ARTRITE REACTIVA
\end{tabular}} \\
\hline Artrite Gotosa & Endocardite Infecciosa \\
\hline Artrite Reumatóide & Sarcoidose \\
\hline Artrite Psoriática & Febre Reumática \\
\hline Doença Inflamatória Intestinal & Doença de Lyme \\
\hline Artrite Séptica & Sífilis Secundária \\
\hline Tuberculose &
\end{tabular}




\section{TERAPÊUTICA}

A escolha da terapêutica deve, idealmente, envolver uma equipa multidisciplinar. Deverá ter em conta a gravidade do quadro, e ter como objectivo a redução das queixas álgicas e inflamação, e prevenção das recidivas ou progressão para doença crónica.

Segundo as guidelines europeias para o tratamento da $\mathrm{SARA}^{26}$, o tratamento de primeira linha deverá incluir repouso absoluto, reabilitação física, anti-inflamatórios não esteróides (AINEs) e injecção de corticóides intra-articulares. Actualmente, não existe evidência suficiente sugerindo a superioridade de qualquer AINE em particular ${ }^{15,26}$. Em casos resistentes à terapêutica anti-inflamatória convencional, corticosteróides sistémicos ou sulfassalazina poderão ser eficazes. Metotrexato está indicado em doença refractária e persistente com duração superior a 3 meses $^{26,27}$.

Durante a infecção génito-urinária aguda, deverá ser dada antibioterapia adequada, e é também fundamental $\circ$ tratamento dos parceiros sexuais ${ }^{28}$. No entanto, no caso de infecção gastrointestinal, antibioterapia apenas deverá ser fornecida em casos excepcionais. Relativamente ao uso de antibióticos durante o episódio de AR, não existe consenso. Yli-Kerttula et a ${ }^{29}$ demonstraram que o uso de antibióticos durante a fase aguda poderia prevenir a progressão para artropatia crónica. Contudo, segundo Laasila e colaboradores ${ }^{30}$, esse benefício apenas se verifica para casos de AR pós-infecção por C. trachomatis.

Agentes queratinolíticos, tais como o ácido salicílico, e corticosteróides tópicos costumam ser suficientes para o controlo das lesões cutâneas associadas a AR. Derivados da vitamina $D$ tópicos são alternativa na presença de lesões cutâneas ligeiras a moderadas. No caso de lesões graves, ou refractárias à terapêutica tópica, tanto o metotrexato como a acitretina podem ser boas opções (Fig. 5).

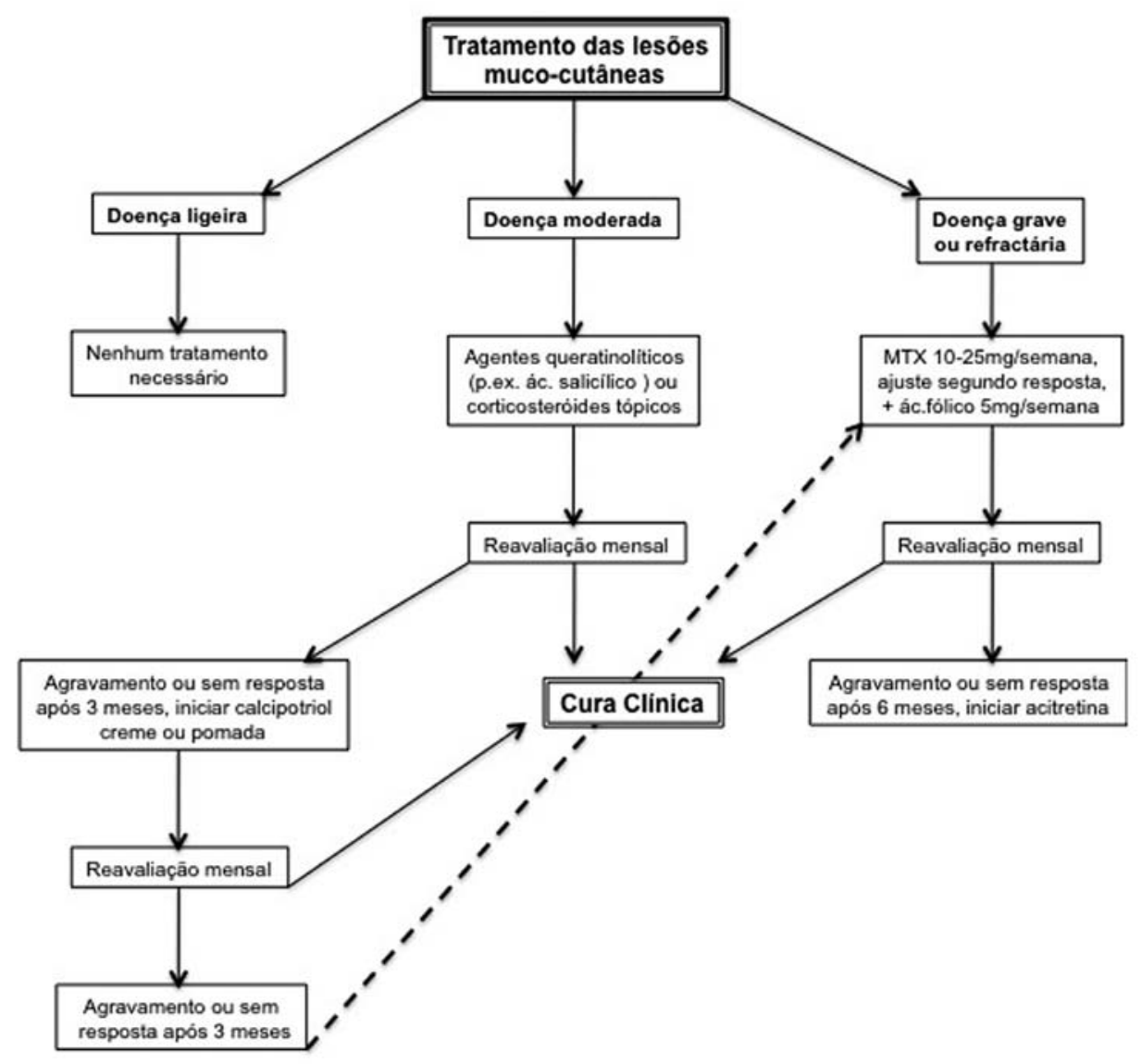

Fig. 5 - Esquema terapêutico recomendado para lesões cutâneas associadas a Artrite Reactiva. Adaptado de Carlin EM, Keat AC: European guidelines for the management of sexually acquired reactive arthritis. Int J STD AIDS 12 Supp 3:94-102 (2001). 


\section{PROGNOSTICO}

A AR tem um curso variável. Habitualmente dura entre 3 a 12 meses, podendo resolver espontaneamente ou evoluir para doença crónica. Pode ainda seguir um curso com alternância de períodos de remissão com recidivas, quer de queixas articulares, quer de outros sintomas. Os doentes postivos para o HLA-B27 têm maior risco de desenvolver doença crónica².

\section{CONCLUSÃO}

A AR é uma doença sistémica caracterizada por artrite asséptica, que é desencadeada por uma infecção distante. Nos adultos, a causa mais comum é a infecção génito-urinária a $C$. trachomatis. Trata-se de uma espondiloartropatia associada ao gene HLA-B27, e a lesão patognomónica é a entesite. Além das manifestações articulares, conjuntive e uretrite fazem parte da apresentação típica, tal como várias lesões muco-cutâneas. O diagnóstico depende da identificação de uma infecção recente e dos sinais de espondiloartropatia. A maioria dos doentes recupera sem sequelas, embora alguns possam sofrer episódios recorrentes.

\section{BIBLIOGRAFIA}

1. Kwiatkowska B, Filipowicz-Sosnowska A: Reactive arthritis. Pol Arch Med Wewn 119: 60-5 (2009).

2. Wu IB, Scwartz RA: Reiter's syndrome: the classic triad and more. J Am Acad Dermatol 59: 113-21 (2008).

3. Ford DK: Non-gonococcal urethritis and Reiter's syndrome: personal experience with etiological studies during 15 years. Can Med Assoc J 99: 900-10 (1968).

4. Carter JD, Hudson AP: Reactive arthritis: Clinical aspects and medical management. Rheum Dis Clin North Am 35: $21-44$ (2009).

5. Gottlieb NL, Altman RD: An ethical dilemma in rheumatology: should the eponym Reiter's syndrome be discarded? Semin Arthritis Rheum 32:207 (2003).

6. Sieper J, Braun J, Kingsley GH: Report on the Fourth International Workshop on Reactive Arthritis. Arthritis Rheum 43: 720-34 (2000).

7. Keat $A$ : Reactive arthritis. In Wolff $K$, Goldsmith LA, Ketz SI, Gilchrest BA, Paller AS, Leffell DJ (eds), Fitzpatrick's Dermatology in General Medicine, $7^{\text {th }}$ ed., New York, McGraw-Hill 2008, pp 207-214.

8. Bas S, Scieux C, Vischer TL: Male sex predominance in Chlamydia trachomatis sexually acquired reactive arthritis: are women more protected by anti-chlamydia antibodies? Ann Rheum Dis 60: 605-11 (2001).

9. Carter JD, Hudson AP: The evolving story of Chlamydia-induced reactive arthritis. Curr Opin Rheumatol 22: 424-30 (2010).

10. Reveille JD: HLA-B27 and the seronegative spondyloarthropathies. Am J Med Sci 316:239-49 (1998).

11. Braun J, Tuszewski $M$, Eggens $U$, Mertz A, et al: Nested polymerase chain reaction strategy simultaneously targeting DNA sequences of multiple bacterial species in inflammatory joint diseases. I. Screening of synovial fluid samples of patients with spondyloarthropathies and other arthritides. J Rheumatol 214: 1092-100 (1997).

12. Pavlica L, Draskovi N, Kuljic-Kapulica N, Nikolic D: Isolation of Chlamydia trachomatis or Ureaplasma urealyticum from the synovial fluid of patients with Reiter's syndrome. Voinosanit Pregl 60: 5-10 (2003).

13. Gerard HC, Branigan PJ, Schumacher HR Jr, Hudson AP: Synovial Chlamydia trachomatis in patients with reactive arthritis/Reiter's syndrome are viable but show aberrant gene expression. J Rheumatol 25: 734-42 (1998).

14. Ramos M, Alvarez I, Sesma L, Logean A, et al: Molecular mimicry of an HLA-B27-derived ligand of arthritis-linked subtypes with Chlamydial proteins. J Biol Chem 277: 37573-81 (2002).

15. Hamdulay SS, Glynne SJ, Keat A: When is arthritis reactive? Postgrad Med J 82: 446-53 (2006).

16. Koga T, Myashita T, Watanabe T, Imadachi S, et al: Reactive arthritis which occurred one year after acute chlamydial urethritis. Inter Med 47: 663-6 (2008).

17. Edwards L, Hansen RC: Reiter's syndrome of the vulva: The psoriasis spectrum. Arch Dermatol 128: 811-4 (1992).

18. Hay EM: Reiter's syndrome and reactive arthritis. $\mathrm{Br}$ J Rheumatol 30: 474-5 (1991).

19. Keat $A$ : Reiter's syndrome and reactive arthritis in perspective. N Engl J Med 309: 1606-15 (1983).

20. Wilkens RF, Arnett FC, Bitter T, Calin A, et al: Reiter's syndrome: Evaluation of preliminary criteria for definite disease. Arthritis Rheum 14: 767-72 (1981).

21. Sousa AE, Gurgel A, Sousa J, Alencar E, et al: Síndrome de Reiter: Relato de caso. An Bras Dermatol 78: 323-30 (2003). 
22. Dimitrova V, Valtchev I, Yordanova H, Haidudova $D$, et al: Keratoderma blennorrhagicum in a patient with Reiter syndrome. Journal of IMAB 1: 68-71 (2008).

23. Amor B: Reiter's syndrome: Diagnosis and clinical features. Rheum Dis Clin North Am 24: 677-95 (1998).

24. Satko SG, Iskandar SS, Appel RG: IgA nephropathy and Reiter's syndrome: Report of two cases and review of the literature. Nephron 84: 177-82 (2000).

25. Mirowski GW: Comment on: Callen JP: The spectrum of Reiter's disease J Am Acad Dermatol 1979;1-75-7. J Am Acad Dermatol 52: 1044 (2005).

26. Carlin EM, Keat AC: European guidelines for the management of sexually acquired reactive arthritis.
Int J STD AIDS 12 Supp 3: 94-102 (2001).

27. Nanke Y, Yago T, Kobashigawa T, Kotaka S: Efficacy of methothrexate in the treatment of a HLA-B27-positive Japanese patient with reactive arthritis. Jpn J Clin Immunol 33: 283-5 (2010).

28. Borges-Costa J, Pacheco D, Pereira F, Marques Gomes M: Artritis reactiva por Chlamydia trachomatis: importancia del rastreo y tratamiento de la pareja. Actas Dermosifiliogr 101: 730-2 (2010).

29. Yli-Kerttula T, Luukkainen R, Yli-Kerttula U, Mottonen $T$, et al: Effect of a three-month course of ciprofloxacin on the late prognosis of reactive arthritis. 62: 880-4 (2003).

30. Laasila K, Laasonen L, Leirisalo-Repo M: Antibiotic treatment and long term prognosis of reactive arthritis. Ann Rheum Dis 62: 655-8 (2003). 